\title{
Initial Surface Absorption of Cement Combination Concrete
}

\author{
Folagbade, S.O. ${ }^{1}$
}

\begin{abstract}
This paper investigated the initial surface absorption (ISAT) of concrete using Portland cement (PC) and some binary and ternary cement combinations containing fly ash (FA), silica fume (SF) and metakaolin (MK) as partial replacements for PC at equal water/ cement ratios and strengths. At equal water/cement ratios, the cement combination concretes have higher ISAT values than PC concrete at 28 days and the disparity reduced with increasing curing age due to improved pozzolanic reactivity of the supplementary cementitious materials. SF and MK as binary and ternary cement components performed better than FA due to their higher fineness, improved particle packing and higher pozzolanic reactivity. At equal strengths, FA binary cement concretes have the lowest ISAT values and these reduced with increasing content of FA. At total replacement levels more than $20 \%$, all the ternary cement concretes have lower ISAT values than PC concrete and the values reduced with increasing total replacement level due to the beneficial effect of FA.
\end{abstract}

Keywords: Blended cement; concrete; initial surface absorption; permeation resistance; supplementary cementitious materials.

\section{Introduction}

Cement combinations could be used to produce durable concretes at reduced cost and environmental impact than the conventional Portland cement (PC) concrete [1]. However, while BS EN 197- 1 [2] permits the use of silica fume (SF), metakaolin (MK, a natural calcined pozzolana), fly ash (FA) and Ground Granulated Blast-furnace Slag (GGBS) of up to $10 \%, 35 \%, 55 \%$ and $95 \%$ respectively, data from the European Ready Mixed Concrete Organisation [3] showed that the total content of these supplementary cementitious materials (SCMs) in readymixed concrete, which are majorly FA and GGBS, is less than $20 \%$ of the total cement consumption. Hence, the patronage and use of higher quantities of these SCMs would make concrete cheaper and more environmentally compatible.

The resistance of the surface zone of concrete to permeation is an important indication of the quality of concrete. Hence, to provide more information on the permeation resistance and support the use of cement combination concrete, this paper investigated the initial surface absorption of concretes containing PC, FA, SF, and MK.

1. Department of Building, Faculty of Environmental Design and Management, Obafemi Awolowo University, Ile-Ife, 0220005, NIGERIA

Email: samuelfolagbade@yahoo.com

Note: Discussion is expected before November, $1^{\text {st }} 2018$, and will be published in the "Civil Engineering Dimension", volume 21, number 1, March 2019.

Received 05 July 2018; revised 16 September 2018; accepted 17 September 2018
The initial surface absorption test is a low pressure assessment of the uniaxial water absorption per unit area of the surface zone (i.e. zone immediately behind the surface) of a concrete at a stated interval (ranging from 10 minutes to 1 hour from the start of the test) and applied head of $200 \mathrm{~mm}$ of water which is slightly greater than that which would be caused by driving rain [4]. Also, the initial surface absorption after 10 minutes (ISAT 10) is sufficient for determining the resistance of the surface zone of concrete (which protects reinforcing steel against corrosion) against water penetration from driving rain [4].

SF and MK particles are characterized by high fineness, close packing and high hydration reaction and would improve the strength and permeation resistance of concrete [5-13]. However, they are costly and their use would result in workability problems [14-18]. Fly ash, which is cheaper and characterised by low water demand and improved workability [19-21], has poor performance at early ages [9]. However, its continuous pozzolanic reaction would improve the resistance of concrete to permeation at later ages [22-24]. Hence, ternary combinations of PC, FA, and SF or MK would reduce the water demand and superplasticiser dosage associated with SF and MK, compensate for the slow rates of reactions of FA at early ages and enhance the early and later-age performance of concrete [20, $22,25-27]$.

Furthermore, while concrete in practice is specified on the basis of strength, most studies have been carried out at different water/cement ratios thus preventing cross deduction between results and 
equal basis for the comparison of the performance of the SCMs. Hence, this paper investigated the ISAT 10 of PC concrete, binary cement concretes containing FA, SF, and MK as partial replacements for $\mathrm{PC}$ and ternary cement concretes containing PC, FA, and $\mathrm{SF}$ or $\mathrm{MK}$ at equal water/cement ratios and strengths.

\section{Experimental Materials and Methods}

The cements were Portland cement (PC, 42.5 strength class) conforming to BS EN 197- 1 [2], Class F fly ash (FA) conforming to BS EN 450- 1 [28] and silica fume (SF) in a slurry form (50:50 solid/water ratio by weight) conforming to BS EN 13263- 1 [29] and metakaolin (MK) conforming to BS EN 197- 1 [2]. The aggregates consisted of $0 / 4 \mathrm{~mm}$ fine aggregates and $4 / 10 \mathrm{~mm}$ and $10 / 20 \mathrm{~mm}$ coarse aggregates. The coarse aggregates were uncrushed and they come in varied shapes. The properties of the cements and aggregates are respectively presented in Tables 1 and 2 .

Table 1. Properties of Cements

\begin{tabular}{lrrrr}
\hline \multirow{2}{*}{ Property } & \multicolumn{5}{c}{ Cements } \\
\cline { 2 - 5 } & PC & FA & SF & MK \\
\hline Blaine fineness, $\mathrm{m}^{2} / \mathrm{kg}$ & 395 & 388 & $*$ & 2588 \\
Loss on ignition, \% a) & 1.9 & $6.1 \mathrm{~b})$ & 2.7 & 0.9 \\
Particle density, g/cm ${ }^{3}$ & 3.17 & 2.26 & 2.17 & 2.51 \\
\% retained by $45 \mu \mathrm{m}$ sieve b) & - & 11.0 & - & - \\
\hline Particle size distribution, cumulative \% passing by mass ${ }^{\mathrm{c}}$ & \\
$125 \mu \mathrm{m}$ & 100.0 & 100.0 & 100.0 & 100.0 \\
$100 \mu \mathrm{m}$ & 98.2 & 99.2 & 100.0 & 100.0 \\
$75 \mu \mathrm{m}$ & 93.2 & 96.5 & 100.0 & 99.8 \\
$45 \mu \mathrm{m}$ & 81.8 & 87.0 & 100.0 & 99.4 \\
$25 \mu \mathrm{m}$ & 57.1 & 66.2 & 98.8 & 96.0 \\
$10 \mu \mathrm{m}$ & 30.1 & 40.6 & 93.8 & 76.2 \\
$5 \mu \mathrm{m}$ & 13.5 & 24.1 & 87.5 & 50.7 \\
$2 \mu \mathrm{m}$ & 5.6 & 10.9 & 85.5 & 18.2 \\
$1 \mu \mathrm{m}$ & 2.9 & 4.8 & 78.7 & 4.7 \\
$0.7 \mu \mathrm{m}$ & 1.3 & 1.9 & 50.7 & 1.4 \\
$0.5 \mu \mathrm{m}$ & 0.2 & 0.3 & 10.5 & 0.1 \\
\hline
\end{tabular}

* Fineness for $\mathrm{SF}=15,000-30,000 \mathrm{~m}^{2} / \mathrm{kg}$ [30]

a) In accordance with BS EN 196-2 [31]

b) In accordance with BS EN 450- 1 [28]

c) Obtained with the Laser Particle Sizer

Table 2. Properties of Fine and Coarse Aggregates

\begin{tabular}{lccc}
\hline \multirow{2}{*}{ Property } & \multicolumn{3}{c}{ Aggregates a) } \\
\cline { 2 - 4 } & Fine & \multicolumn{2}{c}{ Coarse } \\
\cline { 2 - 4 } & $0 / 4 \mathrm{~mm}$ & $4 / 10 \mathrm{~mm}$ & $10 / 20 \mathrm{~mm}$ \\
\hline Shape, visual & - & Varied & Varied \\
Surface texture, visual & - & Rough & Smooth \\
Particle density b) & 2.6 & 2.6 & 2.6 \\
Water absorption, \%c) & 1.0 & 1.7 & 1.2 \\
\% passing 600 $\mu \mathrm{m}$ sieve & 55.0 & - & - \\
\hline a) Aggregates were obtained from Wormit Quarry. \\
b) In accordance with BS EN 1097-6 [32] \\
c) In accordance with BS EN 1097-6 [32], Laboratory-dry \\
condition
\end{tabular}

Concrete was designed in accordance with the BRE Design Guide [33] using saturated surface-dry (SSD) aggregates at a free water content of $165 \mathrm{~kg} / \mathrm{m}^{3}$ and water/cement ratios of $0.35,0.50$, and 0.65 . The experiment (mixing of concrete and curing and testing specimens) was carried out with potable water, conforming to BS EN 1008 [34]. A superplasticiser based on carboxylic ether polymer, conforming to EN 934-2 [35], was applied during mixing to achieve a consistence level of S2 defined by a nominal slump of 50-90 $\mathrm{mm}$ in accordance with BS EN 206- 1 [36].

Concrete was prepared in accordance with BS EN 12390- 2 [37] and the specimens were cast and cured under a damp cover for about 24 hours before being demoulded and cured in water tanks. The compressive strength and ISAT tests were carried out on the specimens. Compressive strength was determined in accordance with BS EN 12390- 3 [38] using 100 $\mathrm{mm}$ cubes at the curing age of 28 days at the water/cement ratios of $0.35,0.50$ and 0.65 . ISAT 10 at the curing ages of 28,90 and 180 days were obtained in accordance with BS 1881- 208 [4] using $150 \mathrm{~mm}$ cubes subjected to water absorption at room temperature $\left(20^{\circ} \mathrm{C}\right)$. Since absorption into concrete is a function of the drying temperature and immersion duration [39], each specimen was oven-dried to constant mass at $105 \pm 5^{\circ} \mathrm{C}$ (to ensure a uniform basis for the comparison and repeatability of the results), cooled to room temperature in a desiccator containing silica gel and subjected to a pressure of $200 \mathrm{~mm}$ head of water (Figure 1). The tap was turned off after 10 minutes to remove the applied water head and the average distance moved by water along the capillary tube in a minute, over three readings, was obtained and multiplied by the calibration factor of the tube, obtained in accordance with BS 1881- 208 [4], to obtain the ISAT 10 values for the specimens (Equation 1).

$\operatorname{ISAT}_{10}=\mathrm{N}_{10} \times \mathrm{C}_{\mathrm{f}}$

where $\operatorname{ISAT}_{10}=$ Initial surface absorption 10 minutes after water first touched the surface of concrete.

$\mathrm{N}_{10}=$ Number of scale divisions moved, in a minute, 10 minutes after water first touched the surface of concrete.

$\mathrm{C}_{\mathrm{f}}=$ Calibration factor of capillary tube determined in accordance with BS 1881- 208 [4].

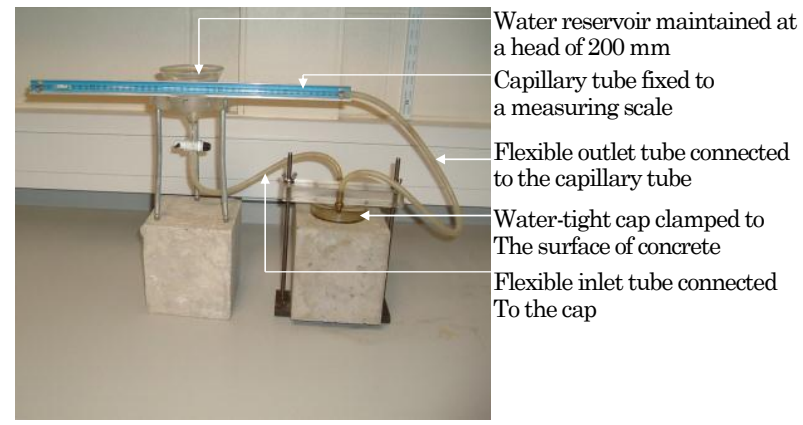

Figure 1. A Typical ISAT Set-up 


\section{Analysis and Discussion of Results}

\section{Initial Surface Absorption of Binary Cement Concretes at Equal Water/Cement Ratios}

Figures 2 and 3 present the ISAT 10 of PC and FA, $\mathrm{SF}$ and MK binary cement concretes at the water/ cement ratios of $0.35,0.50$ and 0.65 . As expected, the Figures show that ISAT 10 increased with increasing water/cement ratio and reduced with increasing curing age. Compared with PC, Figure 2 shows that ISAT 10 of FA binary cement concretes increased with increasing content of FA. The increase must be due to the reduction in the $\mathrm{PC}$ and $\mathrm{Ca}(\mathrm{OH})_{2}$ contents (dilution effect) and the delayed pozzolanic reaction of FA $[9,40]$. Figure 3 also shows that ISAT 10 increased with increasing contents of SF and MK up to 90 days. However, the disparity between the ISAT 10 of PC concrete and that of SF and MK binary cement concretes reduced with increasing age such that at 180 days, the ISAT values were comparable with that of PC concrete. Compared with FA, the higher resistance to permeation of SF and MK must be due to their higher fineness resulting in improved packing and more nucleation sites for improved pozzolanic reaction to reduce pore size and porosity within the paste and at the interface transition zones between the paste and the aggregates despite the dilution effect $[5,12,13]$. Compared with MK, the higher fineness of SF must have also resulted in the lower ISAT values of the SF binary cement concretes than the MK binary cement concretes at equal replacement levels.

\section{Initial Surface Absorption of Ternary Cement Concretes at Equal Water/Cement Ratios}

Figures 4-6 present ISAT 10 of PC, FA binary cement and SF and MK ternary cement concretes at the total replacement levels of 20,35 and $55 \%$ and water/cement ratios of $0.35,0.50$ and 0.65 . Compared with the respective FA binary cement concretes, the addition of SF and MK as ternary cement components (to partly replace the FA contents) reduced ISAT 10 with increasing content at all the ages. Compared with PC, the ternary cement concretes have higher ISAT 10 at 28 days and the values reduced with increasing age such that at 180 days the values became comparable with that of PC concrete. As stated above, the improved performance of the ternary cement concrete would be due to improved packing and high pozzolanic reactivity of the ternary cement components (i.e., SF and MK) within the paste matrix and at the interface zone between the paste and the aggregates. Also, the higher fineness of SF must have also resulted in the lower ISAT 10 of the SF ternary cement concretes than the MK ternary cement concretes at equal replacement levels.
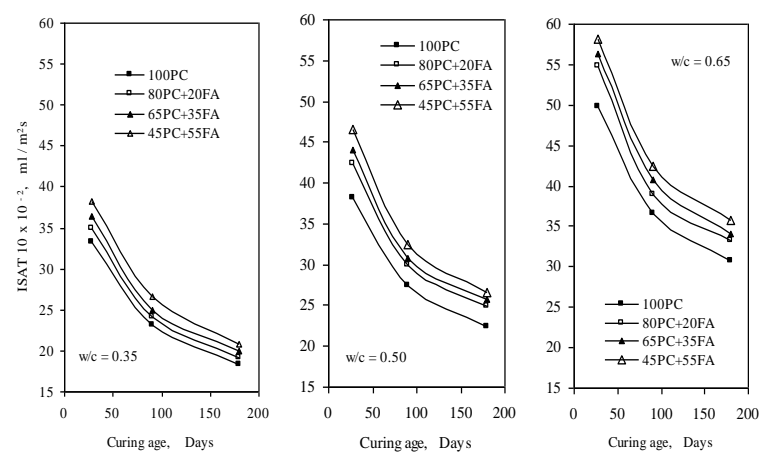

Figure 2. ISAT 10 of $\mathrm{PC}$ and FA Binary Cement Concretes at the Water/Cement Ratios of 0.35, 0.50 and 0.65
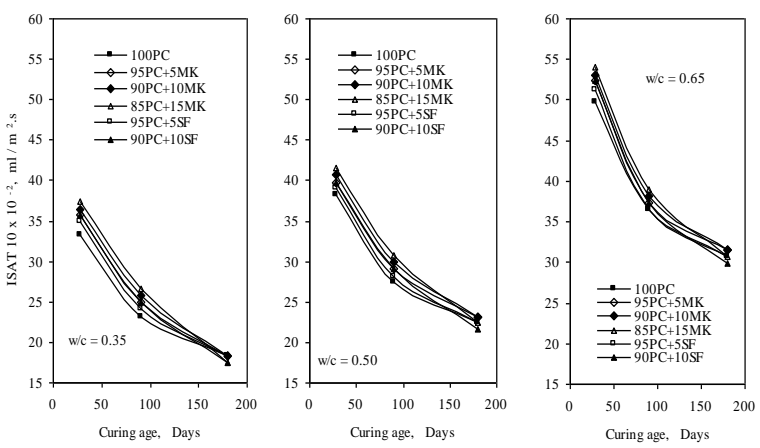

Figure 3. ISAT 10 of $\mathrm{PC}$ and SF and MK Binary Cement Concretes at the Water/Cement Ratios of $0.35,0.50$ and 0.65
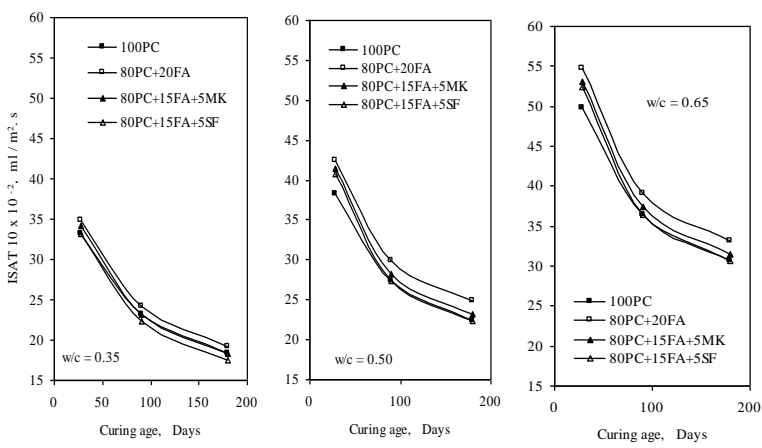

Figure 4. ISAT 10 of PC, FA Binary Cement and SF and MK Ternary Cement Concretes at 20\% Total Replacement Level and Water/Cement Ratios of 0.35, 0.50 and 0.65
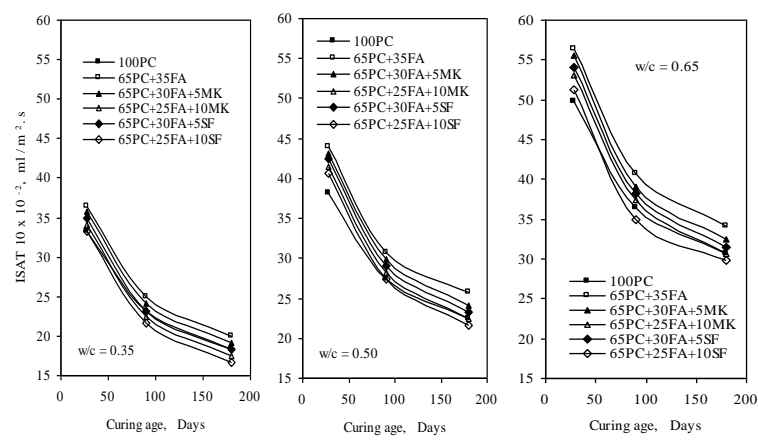

Figure 5. ISAT 10 of PC, FA Binary Cement and SF and MK Ternary Cement Concretes at 35\% Total Replacement Level and Water/Cement Ratios of 0.35, 0.50 and 0.65 

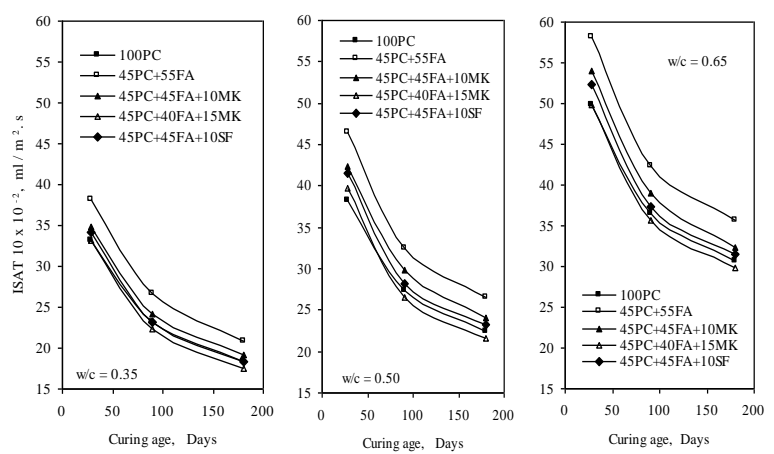

Figure 6. ISAT 10 of PC, FA Binary Cement and SF and MK Ternary Cement Concretes at 55\% Total Replacement Level and Water/Cement Ratios of 0.35, 0.50 and 0.65

\section{Initial Surface Absorption of Cement Com- bination Concretes at Equal Strengths}

Figures 7 and 8 show that cube compressive strengths of concretes at 28 days reduced with increasing water/cement ratio. Compared with PC, while the addition of FA as a binary cement component reduced concrete strength with increasing content, the addition of SF and MK resulted in comparable strengths with PC concrete. Compared with the FA binary cement concretes, the addition of $\mathrm{SF}$ and MK as ternary cement components resulted in ternary cement concretes with improved strength.

Since concrete is specified in practice on the basis of strength at 28 days, ISAT 10 values of the concretes were examined at equal 28-day strengths. The cube compressive strengths (Figures 7 and 8) and ISAT 10 values of the concretes at 28 days (Figures 2-6) at the water/cement ratios of $0.35,0.50$ and 0.65 were interpolated to obtain the ISAT 10 of concretes at the 28-day strengths of $35,40,45$ and $50 \mathrm{~N} / \mathrm{mm}^{2}$ (Table 3). Apart from falling within the range of strengths that would commonly be used in practice, these strengths also satisfy most of the strength requirements in BS EN 206-1 [35] and BS 8500 [41,42].

Table 3 shows that ISAT 10 values of concretes, at equal strengths, were achieved at different water/ cement ratios and they reduced with increasing strength. Compared with PC, all the FA binary cement concretes have lower ISAT 10 values at equal strengths and these values decreased with increasing content of FA. On the other hand, all the SF and MK binary cement concretes have higher ISAT 10 values than PC concrete and the values increased with increase in their contents. Compared with the respective FA binary cements, the ternary cement concretes have higher ISAT 10 values at equal strengths. Whereas, the ternary cement concretes have higher ISAT 10 values than PC concrete at the total replacement levels of $20 \%$, the values were lower than that of PC concrete at the total replacement levels of $35 \%$ and they reduced with increasing total replacement level to $55 \%$. This must be due to the beneficial effect of $\mathrm{FA}$ at equal strengths. Hence, high content of FA would play a major role in reducing the initial surface absorption of concrete specified on the basis of strength. These results indicate that, if appropriate mix combination is used, cement combination would result in better resistance of concrete to permeation at equal strengths [43,44]. Table 3 also shows that, at equal strengths, MK binary and ternary cement concretes have lower ISAT 10 values than SF binary and ternary cement concretes at equal replacement levels.
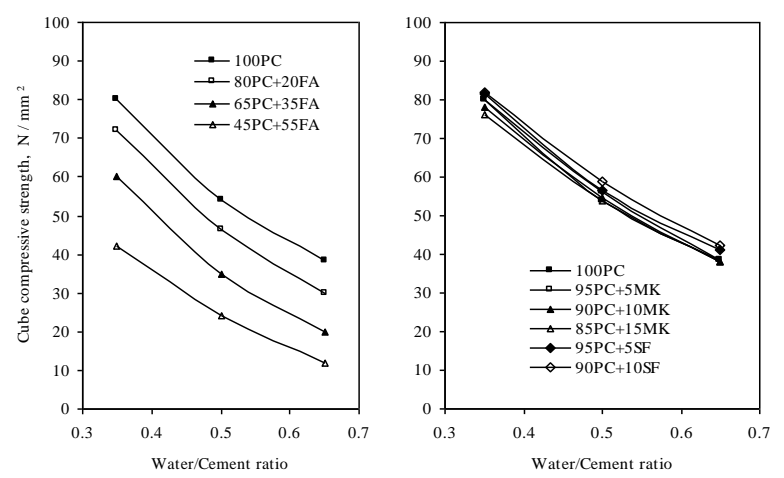

Figure 7. Cube Compressive Strength of PC and FA, SF and MK Binary Cement Concretes at the Water/Cement Ratios of $0.35,0.50$ and 0.65
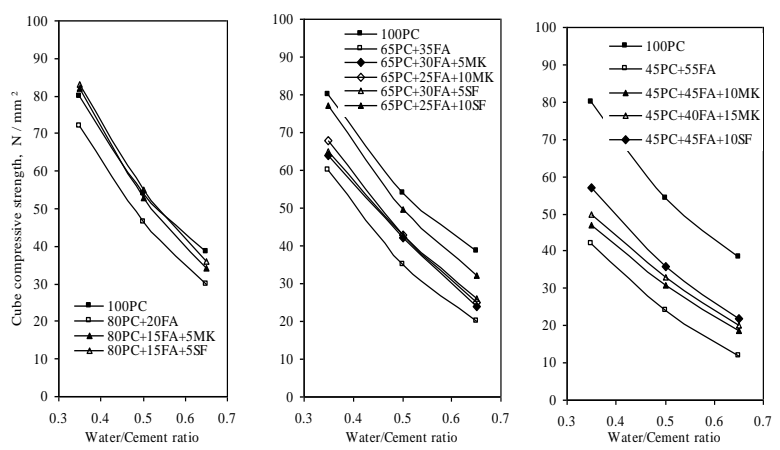

Figure 8. Cube Compressive Strength of PC and Ternary Cement Concretes at the Water/Cement Ratios of $0.35,0.50$ and 0.65 and Total Replacement Levels of 20, 35 and $55 \%$

\section{Conclusion}

This study investigated the effect of FA, SF and MK on the ISAT 10 of PC concrete at equal water/cement ratios and strengths and the following conclusions have been drawn:

1. ISAT 10 increased with increasing water/cement ratio and reduced with increasing curing age and compressive strength.

2. At equal water/cement ratios, the SCMs have higher ISAT values than PC concrete. However, while FA binary cement concretes have considerably higher ISAT values than $\mathrm{PC}$ concrete due to delayed pozzolanic reactivity, SF and MK have values comparable with that of $\mathrm{PC}$ due to their higher fineness and improved particle packing 
Table 3. ISAT 10 values of concretes at 28-day strengths of 35, 40, 45 and $50 \mathrm{~N} / \mathrm{mm}^{2}$

\begin{tabular}{|c|c|c|c|c|c|c|c|c|}
\hline \multirow{3}{*}{ MIX COMBINATION } & \multicolumn{8}{|c|}{ ISAT $10 \times 10^{-2}, \mathrm{ml} / \mathrm{m}^{2} . \mathrm{s}$} \\
\hline & \multicolumn{2}{|c|}{$35 \mathrm{~N} / \mathrm{mm}^{2}$} & \multicolumn{2}{|c|}{$40 \mathrm{~N} / \mathrm{mm}^{2}$} & \multicolumn{2}{|c|}{$45 \mathrm{~N} / \mathrm{mm}^{2}$} & \multicolumn{2}{|c|}{$50 \mathrm{~N} / \mathrm{mm}^{2}$} \\
\hline & $\mathrm{w} / \mathrm{c}$ & ISAT 10 & $\mathrm{w} / \mathrm{c}$ & ISAT 10 & $\mathrm{w} / \mathrm{c}$ & ISAT 10 & $\mathrm{w} / \mathrm{c}$ & ISAT 10 \\
\hline $100 \% \mathrm{PC}$ & * & * & 0.63 & 47.9 & 0.57 & 42.8 & 0.53 & 40.0 \\
\hline $80 \% \mathrm{PC}+20 \% \mathrm{FA}$ & 0.59 & 49.3 & 0.55 & 46.0 & 0.51 & 43.1 & 0.47 & 40.5 \\
\hline $80 \% \mathrm{PC}+15 \% \mathrm{FA}+5 \% \mathrm{MK}$ & 0.63 & 51.3 & 0.59 & 48.0 & 0.55 & 44.9 & 0.51 & 42.2 \\
\hline $80 \% \mathrm{PC}+15 \% \mathrm{FA}+5 \% \mathrm{SF}$ & * & * & 0.61 & 48.9 & 0.57 & 45.7 & 0.53 & 42.7 \\
\hline $65 \% \mathrm{PC}+35 \% \mathrm{FA}$ & 0.50 & 44.0 & 0.46 & 41.6 & 0.43 & 39.9 & 0.40 & 38.5 \\
\hline $65 \% \mathrm{PC}+30 \% \mathrm{FA}+5 \% \mathrm{MK}$ & 0.55 & 46.8 & 0.51 & 43.9 & 0.47 & 41.4 & 0.44 & 39.7 \\
\hline $65 \% \mathrm{PC}+25 \% \mathrm{FA}+10 \% \mathrm{MK}$ & 0.56 & 45.7 & 0.52 & 42.9 & 0.48 & 40.3 & 0.45 & 38.6 \\
\hline $65 \% \mathrm{PC}+30 \% \mathrm{FA}+5 \% \mathrm{SF}$ & 0.56 & 46.6 & 0.52 & 43.8 & 0.48 & 41.2 & 0.44 & 39.0 \\
\hline $65 \% \mathrm{PC}+25 \% \mathrm{FA}+10 \% \mathrm{SF}$ & 0.61 & 48.2 & 0.57 & 45.3 & 0.53 & 42.6 & 0.49 & 40.2 \\
\hline $45 \% \mathrm{PC}+55 \% \mathrm{FA}$ & 0.40 & 40.6 & 0.36 & 38.7 & ** & $* *$ & $* *$ & $* *$ \\
\hline $45 \% \mathrm{PC}+45 \% \mathrm{FA}+10 \% \mathrm{MK}$ & 0.47 & 40.6 & 0.42 & 37.9 & 0.37 & 35.7 & $* *$ & $* *$ \\
\hline $45 \% \mathrm{PC}+40 \% \mathrm{FA}+15 \% \mathrm{MK}$ & 0.48 & 38.8 & 0.43 & 36.3 & 0.39 & 34.7 & $* *$ & $* *$ \\
\hline $45 \% \mathrm{PC}+45 \% \mathrm{FA}+10 \% \mathrm{SF}$ & 0.50 & 41.5 & 0.46 & 39.2 & 0.42 & 37.2 & 0.39 & 35.8 \\
\hline$\overline{95 \% \mathrm{PC}+5 \% \mathrm{MK}}$ & * & * & 0.63 & 50.3 & 0.58 & 45.5 & 0.54 & 42.4 \\
\hline $95 \% \mathrm{PC}+5 \% \mathrm{SF}$ & $*$ & $*$ & 0.62 & 50.0 & 0.57 & 45.5 & 0.53 & 42.6 \\
\hline $95 \% \mathrm{PC}+5 \% \mathrm{SF}$ & $*$ & $*$ & 0.62 & 50.9 & 0.57 & 46.3 & 0.53 & 43.4 \\
\hline $95 \% \mathrm{PC}+5 \% \mathrm{SF}$ & * & * & $*$ & $*$ & 0.60 & 46.3 & 0.55 & 42.2 \\
\hline $90 \% \mathrm{PC}+10 \% \mathrm{SF}$ & $*$ & * & $*$ & * & 0.62 & 49.2 & 0.57 & 44.7 \\
\hline
\end{tabular}

and pozzolanic reactivity. Hence, compared with FA binary cement concrete, SF and MK ternary cement concretes have lower ISAT values.

3. At equal strengths, while the addition of SF and MK as binary cement components increased the ISAT of concrete with increasing content, FA as a binary cement component reduced ISAT with increasing content. Consequently, the ISAT of the ternary cement concretes reduced with increasing total replacement level such that they became lower at total replacement levels more than $20 \%$.

4. At equal replacement levels, while SF has higher resistance to initial surface absorption than MK at equal water/cement ratios, MK has higher resistance than $\mathrm{SF}$ at equal strengths.

\section{Acknowledgement}

The Author expressed his gratitude to the Department of Civil Engineering at the University of Dundee in United Kingdom where the research was carried out.

\section{References}

1. Folagbade, S. O., Absorption Characteristics of Cement Combination Concrete Containing Portland Cement, Fly Ash, and Metakaolin, Civil Engineering Dimension, 18(1), 2016, pp. 57-64.

2. BS EN 197- 1: 2000, Cement- Part 1: Composition, Specifications and Conformity Criteria for Common Cements, British Standards Institution, London.

3. European Ready Mixed Concrete Organisation. Available at http://www.ermco.eu/documents. Accessed July 18, 2015.
4. BS 1881- 208: 1996, Testing Concrete- Part 208: Recommendations for the Determination of the Initial Surface Absorption of Concrete, British Standards Institution, London.

5. Mehta, P, K. and Aitcin P. C., Principles Underlying Production of High-Performance Concrete, Cement Concrete and Aggregates, 12, 1990, pp. 70-78.

6. Bentz, D. P., Stutzman, P. E., and Garboczi, E. J., Experimental and Simulation Studies of the Interfacial Zone in Concrete, Cement And Concrete Research, 22(5), 1992, pp. 891-902.

7. Wild, S., Khatib, J. M., and Jones, A., Relative Strength Pozzolanic Activity and Cement Hydration in Superplasticised Metakaolin Concrete, Cement and Concrete Research, 26(10), 1996, pp. 1537-1544.

8. Bai, J., Sabir, B. B., Wild, S., and Kinuthia, J. M., Strength Development in Concrete Incorporating PFA and Metakaolin, Magazine of Concrete Research, 52(3), 2000, pp. 153-162.

9. Hassan, K. E., Cabrera, J. G., and Maliehe, R. S., The Effect of Mineral Admixtures on the Properties of High-Performance Concrete, Cement and Concrete Composites, 22(4), 2000, pp. 267-271.

10. Bai, J. and Wild, S., Investigation of the Temperature Change and Heat of Evolution of Mortar Incorporating PFA and Metakaolin, Cement and Concrete Composites, 24(2), 2000, pp. 201-209.

11. Langan, B. W., Weng, K., and Ward, M. A., Effect of Silica Fume and Fly Ash on Heat of Hydration of Portland Cement, Cement and Concrete Research, 32(7), 2002, pp. 1045-1051.

12. Mindess, S., Young, F. J., and Darwin, D., Concrete, Prentice-Hall, New Jersey, 2003. 
13. Korpa, A., Kowald, T., and Trettin, R., Hydration Behaviour, Structure and Morphology Phases in Advanced Cement Based Systems Containing Micro and Nanoscale Pozzolanic Additives, Cement and Concrete Research, 38(7), 2008, pp. 955-962.

14. Bai, J., Wild, S., Sabir, B.B., and Kinuthia, J.M., Workability of Concrete Incorporating Pulverized Fuel Ash and Metakaolin, Magazine of Concrete Research, 51(3), 1999, pp. 207-216.

15. Bouzoubaa, N., Bilodeau, A., Sivasundaram, V., Fournier, B., and Golden, D. M., Development of Ternary Blends for High Performance Concrete, ACI Material Journal, 10(1), 2004, pp. 19-29.

16. Khatib, J. M. and Clay, R. M., Absorption Characteristics of Metakaolin Concrete, Cement and Concrete Research, 34(1), 2004, pp. 19-29.

17. Wong, H. S. and AbdulRazak, H., Efficiency of Calcined Kaolin and Silica Fume as Cement Replacement Material for Strength Performance, Cement and Concrete Research, 35(4), 2005, pp. 696-702.

18. Park, C. K., Noh, M. H., and Park, T. H., Rheological Properties of Cementitious Materials Containing Mineral Admixtures, Cement and Concrete Research, 35(5), 2005, pp. 842-849.

19. Antiohos, S. K., Papadakis, V. G., Chaniotakis, E., and Tsimas, S., Improving the Performance of Ternary Blended Cements by Mixing Different Types of Fly Ashes, Cement and Concrete Research, 37(6), 2007, pp. 877-885.

20. Thomas, M. D. A., Shehata, M. H., Shashiprakash, S. G., Hopkins, D. S., and Cail, K., Use of Ternary Cementitious Systems Containing Silica Fume and Fly Ash in Concrete, Cement and Concrete Research, 29(8), 1999, pp. 1207-1214.

21. Dhir, R. K., McCarthy, M. J., and Paine, K. A., Use of Fly Ash to BS EN 450 in Structural Concrete, Thomas Telford, 2002, 878p.

22. Lam, L., Wong, Y. L., and Poon, C. S., Effect of Fly Ash and Silica Fume on Compressive and Fracture Behaviours of Concrete, Cement and Concrete Research, 28(2), 1998, pp. 271-283.

23. Naik, T. R., Singh, S., and Ramme, B., Mechanical Properties and Durability of Concrete made with Blended Fly Ash, ACI Material Journal, 95(4), 1998, pp. 454-462.

24. Dhir, R. K. and Jones, M. R., Development of Chloride-Resisting Concrete using Fly Ash, Fuel, 78(2), 1999, pp. 137-142.

25. Mehta, P. K. and Gjorv, O. E., Properties of Portland Cement Concrete Containing Fly Ash and Condensed Silica Fume, Cement and Concrete Research, 12(5), 1982, pp. 587-595.

26. Khan, M. I., Lynsdale, C. J., and Waldron, P., Porosity and Strength of PFA/SF/OPC Ternary Blended Paste, Cement and Concrete Research, 30(8), 2000, pp. 1225-1229.

27. Khan, M. I. and Lynsdale, C. J., Strength, Permeability, and Carbonation of High-Performance Concrete, Cement and Concrete Research, 32(1), 2002, pp. 123-131.
28. BS EN 450- 1: 2002, Fly Ash for Concrete- Part 1: Definitions, Specifications and Conformity Criteria, British Standards Institution, London.

29. BS EN 13263: 2005, Silica Fume for Concrete, British Standards Institution, London.

30. Holland, T. C., Silica Fume User's Manual, Silica Fume Association, Lovettsville, VA 22180, USA, 2005.

31. BS EN 196-2: 2005, Methods for Testing CementPart 2: Chemical Analysis of Cement, British Standards Institution, London.

32. BS EN 1097- 6: 2000, Tests for Mechanical and Physical Properties of Aggregates-Part 6: Determination of Particle Density and Water Absorption, British Standards Institution, London.

33. Teychenne, D. C., Franklin, R. E., and Erntroy, H. C., Design of Normal Concrete Mixes, $2^{\text {nd }}$ Ed., amended by B. K. Marsh, Building Research Establishment, Watford, 1997.

34. BS EN 1008: 2002, Mixing Water for ConcreteSpecification for Sampling, Testing, and Assessing the Suitability of Water, Including Water Recovered From Processes in the Concrete Industry, as Mixing Water for Concrete, British Standards Institution, London.

35. BS EN 934-2: 2009, Admixtures for Concrete, Mortar, and Grout- Part 2: Concrete AdmixturesDefinitions, Requirements, Conformity, Marking and Labelling, British Standards Institution, London.

36. BS EN 206-1: 2000, Concrete- Part 1: Specification, Performance, Production and Conformity, British Standards Institution, London.

37. BS EN 12390-2: 2000, Testing Hardened Concrete- Part 2: Making and Curing Specimens for Strength Tests, British Standards Institution, London.

38. BS EN 12390-3: 2002, Testing Hardened Concrete-Part 3: Compressive Strength of Test Specimens, British Standards Institution, London.

39. Lea, F. M., Lea's Chemistry of Cement and Concrete, $4^{\text {th }}$ Ed., Arnold, London, 1998.

40. McCarthy, M. J. and Dhir, R. K., Development of High Volume Fly Ash Cements for Use in Concrete Construction, Fuel, 84, 2005, pp. 14231432.

41. BS 8500-1: 2006, Concrete- Complementary British Standard to BS EN 206-1-Part 1: Method of Specifying and Guidance for The Specifier, British Standards Institution, London.

42. BS 8500-2: 2006, Concrete-Complementary British Standard to BS EN 206-1-Part 2: Specification for Constituent Materials and Concrete, British Standards Institution, London.

43. Dhir, R. K. and Byars, E. A., PFA Concrete: Near Surface Absorption Properties. Magazine of Concrete Research, 43(157), 1991, pp. 219-232.

44. Dias, W.P.S., Nanayakkara, S.M.A., and Ekneligoda, T. C., Performance of Concrete Mixes With OPC-PFA Blends, Magazine of Concrete Research, 55(2), 2003, pp 161-170. 